\title{
Restoration conservation works carried out at the historical Malabadi Bridge, Turkey
}

\author{
H. Sert, S. Y1lmaz, M. Elbir, E. M. Partal, H. Demirci, A. Avşin, \\ M. Nas \& G. S. Turan \\ Ministry of Transport, Maritime Affairs and Communication, \\ General Directorate of Highways, Department of Structures, \\ Division of Historical Bridges, Turkey
}

\begin{abstract}
It is one of the primary tasks of the General Directorate of Highways (KGM) to repair and maintain historic bridges which are of great importance in view of our cultural history in accordance with the projects to be developed or caused to be developed, apart from the recently constructed roads and bridges. Pursuant to the inventory records, it has been observed according to their period of construction (as of December 2014) that there are a total of 1772 bridges in our country grouped according to their method of construction as follows: stone (1682), wooden (29), iron (30), reinforced concrete (31). The historical bridges, the majority of which are located on 1st degree seismic zones and have proven to be durable for centuries, are considered to serve for a long time in case a relationship between the original construction techniques and soil-foundation-river is established. In this context, during the execution of the restoration works which should be carried out in accordance with the least intervention principle, it is of great importance to define the original construction systems of the bridges and their characteristics material wise. In the context of this particular paper, the restoration, conservation works carried out from 2009 through to 2013 by the General Directorate of Highways, at the historical Malabadi Bridge, located on the Batman River in the District of Diyarbakır and constructed in the Seljuk period will be discussed. It is the only stone arch bridge with the largest span in the world surviving to date, having a pointed arch in $40.86 \mathrm{~m}$ spans.
\end{abstract}

Keywords: historical bridges, Malabadi Bridge, restoration, conservation. 


\section{Introduction}

The road networks located in Mesopotamia and Syria by the time of Assyrian and Babylon Civilizations and known to be the first regular road extend through Turkish territory. Penetrating into Turkish border in Cizre, the road extends towards the central Anatolia and used respectively by the Hittites, Persians, Helens, Romans and East Romans while the Seljuks and Ottomans followed the same route at the subsequent times. Since the Romans equipped the roads and passages on the said routes with militaristic and social structures and the way the Romans pursued particular housing policies, the East Romans made no significant alteration in such policies while the Seljuks and Ottomans re-assessed the route and pursued the same within the framework of a much more developed system. As for the bridges which provide uninterrupted services on the road alignments, they have always been regarded as the structures of particular importance due to the fact that that the bridges were not only used by the postal and communication organizations but also the military forces during expeditions and the commercial caravans and the pilgrims. The bridges served as accommodation facilities for the officers employed at the bridges as well as the messengers Çulpan [1], İlter [2], Ortaylı [3], KGM [4]).

\section{Historic Malabadi Bridge: location, status, history and architectural features}

The historic Malabadi Bridge registered in the inventory produced specifically for the bridges of historic nature with the registration number B.09/I.21/N.01 and registered on March 14, 1980 upon resolution of the Conservation Board numbered 11789, is located on Batman Stream which disembogues to Dicle (Tigris) River at Çatakköprü Site in the District of Silvan in Diyarbakır Province and constructed at the narrowest section of the riverbed. The bridge which had been in service for vehicular traffic until construction of the $\mathrm{RC}$ arch bridge to the upstream of the bridge in 1955, hosts Batman Dam the construction of which was completed in 2003 at $750 \mathrm{~m}$ to the upstream (Figure 1).
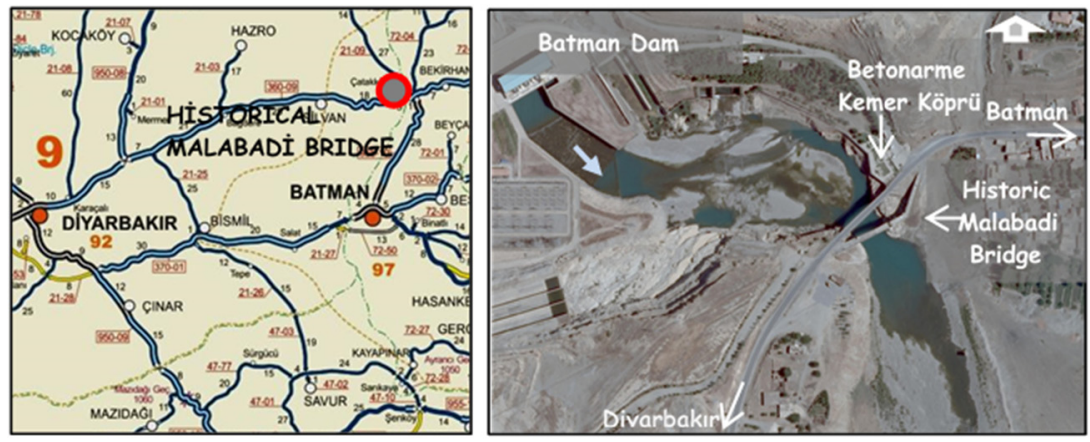

Figure 1: Location of the bridge (KGM [5], Google Earth [6]). 
The bridge located on first degree seismic zone is the largest spanned stone arch bridge in the world with its pointed arch of $40.86 \mathrm{~m}$ spanning. According to the epitaph dated 1147, the bridge which was constructed by Timurtaş b. İlgazi $b$ Artuk during Artuqids period is $220 \mathrm{~m}$ long with 5 spans in total one of which is located on the main span. The efforts to settle the bridge on sound foundation led to an irregular geometry on the plane of the design. The bridge which was constructed through evenly cut squared stones, includes chambers the top layer of which was formed through bricked vault and built for the purpose of attenuating the load received by the foundations while such chambers were separately functioned. The arches of the bridge are bi-centered a profile of $0.40 \mathrm{~m}$ high above the stones of the main arch at a height of $1.20 \mathrm{~m}$ as well as an outstretched archivolt. Uprising as a continuity of spandrel walls, the parapets were constructed by the use of rustication stone. To the upstream of the bridge, there exist triangularly shaped flood splitters while to the downstream side, such flood splitters are circular in form with pointed cones embroidered with human figures, lion and sun reliefs. The frontal pattern of the bridge is asymmetric while the bridge rises at an elevation of 12 to $20 \%$ up to the largest arch and descends at a rate of 17 to $19 \%$ to Batman side which gives the bridge an environmentally harmonious shape.

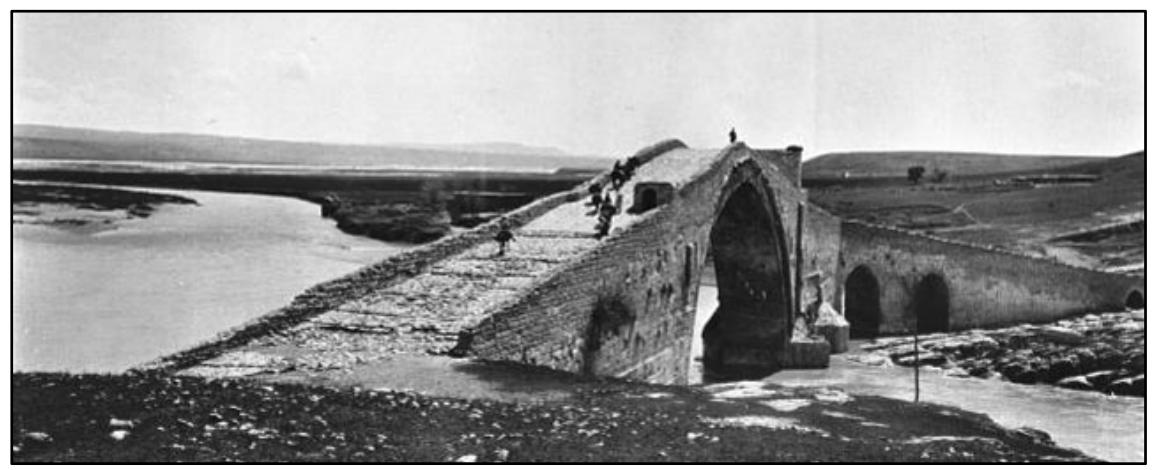

Figure 2: Upstream view of the bridge, G. Bell, 1909 (KGM [7]).

\section{Pre-restoration condition of the bridge}

Malabadi Bridge which provides a passageway for the road on which it is located for centuries has survived to date without any substantial structural damage. However, during repair works carried in 1954 and 1985, the surfaces were plastered by cement base mortar other than the surfaces on the intrados and spandrels of the main arch while the bridge was paved with concrete. In order to prevent the gradually increasing disfiguration of the stones due to the effects of the variable water flow from the nearby dam and clear the traces of the repairs made most lately and which have been deemed not to be in harmony with the original pattern of the bridge, the bridge was included in the program in 2009. (Figures 3-6). 


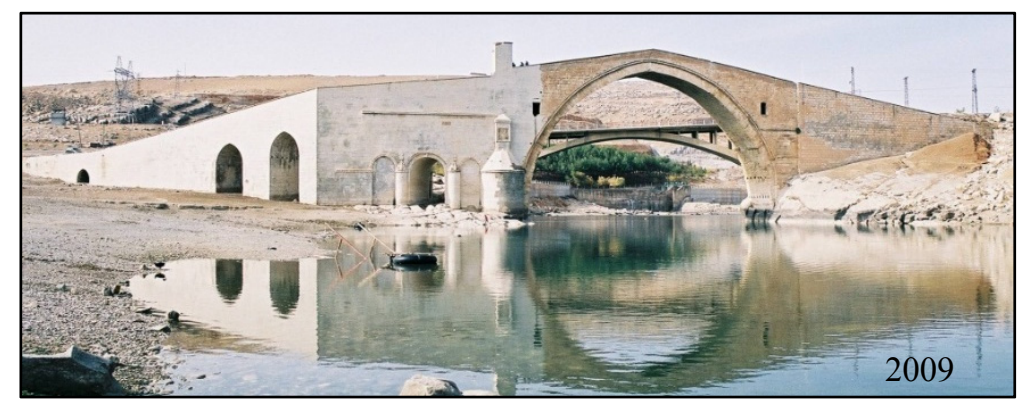

Figure 3: Pre-restoration view of the bridge.
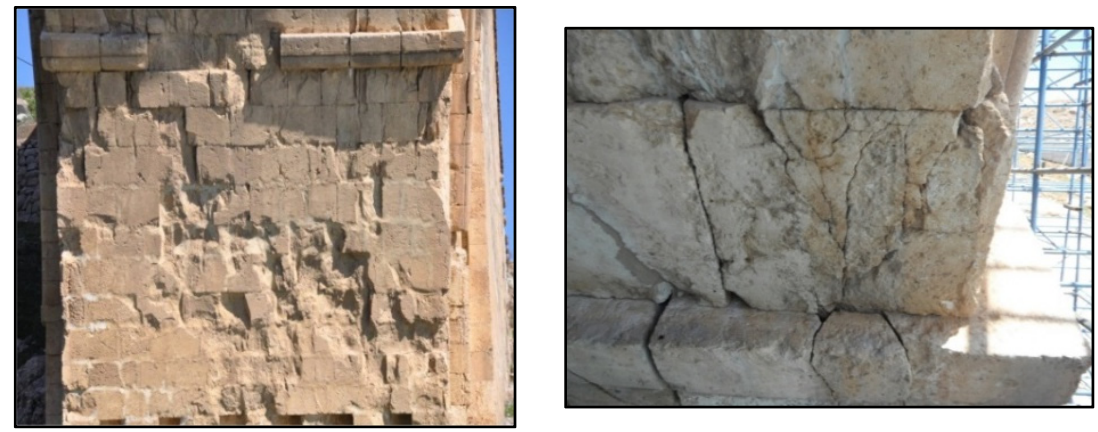

Figure 4: Erosion of main arch Figure 5: Cracks at springer level of stones. arch stones.

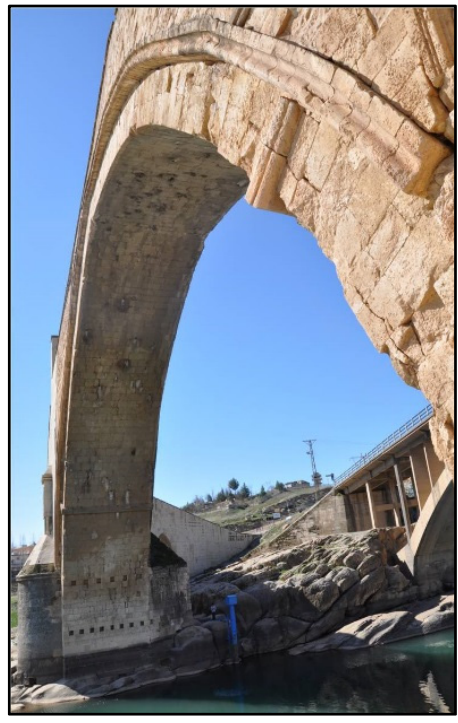

Figure 6: Intrados view of main arch. 
Though the restoration works carried out at Malabadi Bridge in 2009 through to 2013 includes many work items this paper shall summarize the design and application works executed for the conservation of the main constituent of the bridge, that is to say, the stone (KGM [7]; Doğan and Sert [8]; Doğan et al. [9, 10]; Ener and Sert [11]; Sert et al. [12]; Sert and Y1lmaz [13, 14]).

\section{Restoration project}

\subsection{Survey drawings}

During surveys executed on June 2009, the bridge surfaces were scanned in 3D through ground laser scanning method and the bridge and its vicinity were documented with the survey drawings and photographs. Apart from such studies, the structural problems were determined the deteriorations observed on the stone were classified. Accordingly, there observed losses on the surfaces of the original stones in exfoliated form excluding the surfaces plastered during late period repairs, abrasions in coarse porosity form and detachments which may be in the form of various pieces at different dimensions and may get deeper occasionally. In addition, there observed structural and superficial cracks at springer level of the main arch within intrados while it is considered that such cracks are due to the crushed masonry materials and the capillary cracks on the stone. All such visual observations are shown on the visual decay analysis in colored form with legends under the titles of superficial/structural cracks, material and surface losses, floral and faunal deteriorations, joint spaces etc. (Figure 7).

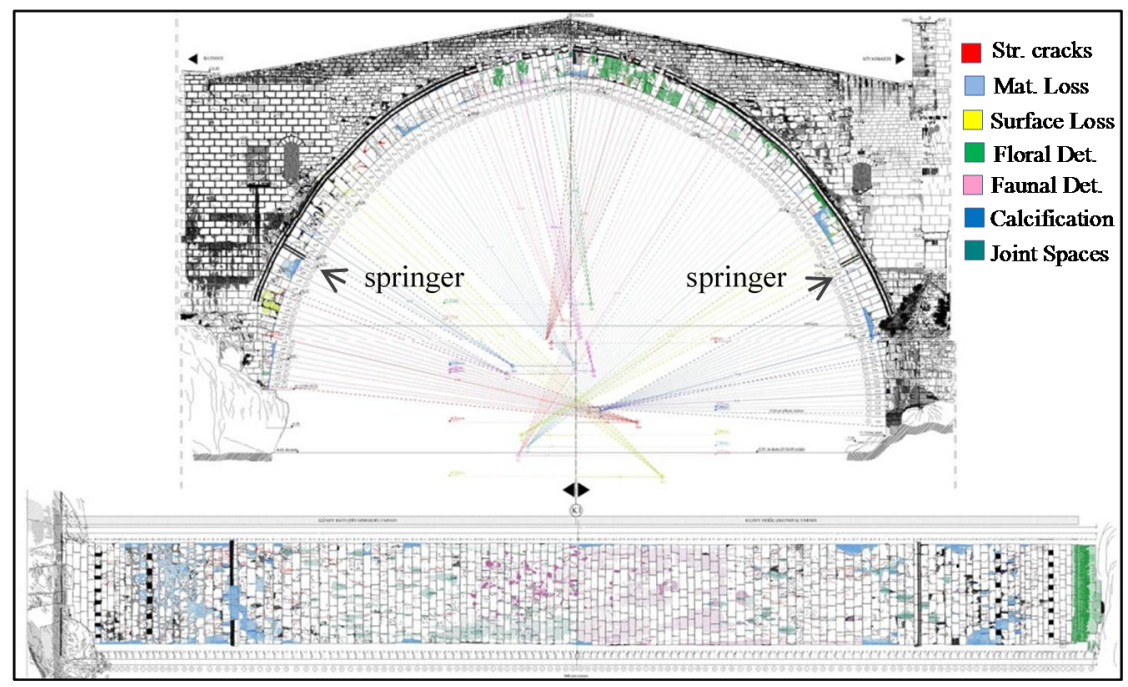

Figure 7: Visual decay form of K1 (main) arch of the bridge. 


\subsection{Technical researches}

The technical researches include sampling the original stones taken from the bridge through drills and mechanical methods and determination of the physical, chemical and mechanical properties and tests to be performed on the stones to be used in the restoration works.

\subsubsection{Stone analysis}

As a consequence of the physical, chemical and mechanical analysis, it has been observed that the original stones used in the bridge contain surplus of fossils and pores up to $0.5 \mathrm{~mm}$ dimension wise and that the stones are in fact fossilized limestone with high abrasion rate and low compressive strength (Table 2). It has been found out that this is the primary reason for the formation of structural cracks due to abrasion, deflocculation and loss of material pieces and crushes observed particularly on the arch stones of the bridge at springer level. The conservation report, issued for the bridge makes several suggestions for application in order to obviate and minimize the deteriorations observed on the surfaces of the original stone and the materials to be used in the conservation works are detailed in Table 1 below (Procedures 1 to 8 with topics) as well as the application methods. In this context, it has been suggested that the layered stains on the surfaces with inscriptions (epitaph) and stones with patterns (bas reliefs) are first cleaned in dry form through stiff plastic brush, thereafter chemical application is made with the introduction of soaked pulp (Table 1; Procedure 1), in order to fill the micro and macro cracks already observed to exist and to be found out in the future, and plastic repair of the stones smaller than $5 \mathrm{~cm}$, application of grout prepared through adding acrylic emulsion (Table 1; Procedures 2, 3, 4, 5), adhesion and replacement of the ruptured pieces of original stones with or without reinforcement (Table 1; Procedures 6,7) and replacement of the excessively abraded stones with new ones (Table 2).

In addition, in order to obviate or minimize the abrasions observed on the surfaces of the stones, it has been recommended to apply surface protective materials on surfaces of the arch stones which are substantially abraded (Table 1; Procedure 8). The standardized stone tests were performed on the material in order to find out the efficacy of this recommendation. The results obtained implied that the abrasion and water absorption values of the original stones on which chemical material was previously applied substantially improved (Table 2).

\subsection{Restitution project}

In order to convey the amendments made to the bridge and its vicinity from the period it was constructed until today to the restitution project in an healthier manner, the photographs at KGM archives and the photographs taken by $20^{\text {th }}$ century travelers Gertrude Bell and architect - archeologist Albert Gabriel were used as well as the documents which pertain to the repair works executed on the bridge in 1954 through 1985. 
Table 1: Materials used in stone conservation and application methods.

Procedure 1: Cleaning: Absorption of ammonium bicarbonate solution of $15 \%$ (1 lt water and $150 \mathrm{~g}$. ammonium bicarbonate) on the surfaces through pulps.

Procedure 2: Gap Filling: Filling the cracks with the grout produced through addition of 1 volume of hydraulic lime and 1.5 to 2 volumes of powdered stone with the incorporation of acrylic emulsion (Primal AC33) of 5\% in gel consistency.

Procedure 3: Gap Filling: Filling the wide and deep cracks with the grout produced through addition of 1 volume of hydraulic lime and 1 volume of tuff (pumice) stone mix in gel consistency with the incorporation of acrylic emulsion (Primal AC33) of 15\%.

Procedure 4: Gap Filling: Strengthening the cracks which cannot be filled through grout injection through addition of acrylic emulsion (Primal AC33) of 5\% and 7\% respectively.

Procedure 5: Plastic Repair: Stone completion with the use of 1 volume of hydraulic lime and 2.5 volume of respective undersized stone with the incorporation of acrylic emulsion (Primal AC33) of 5\%.

Procedure 6: Adhesion with Reinforcement: Adhesion through Araldite AY103HY956 or Raku Tool EL 2200-EH 2900 (or their equivalent) with the addition of epoxy grout thinned through the powder of the relevant stone the viscosity of which less than $500 \mu$.

Procedure 7: Adhesion without Reinforcement: Adhesion through epoxy grout consistency of which is in gel form and made through the powder of the under sieved stone the viscosity of which is $250 \mu$.

Procedure 8: Surface Protection: Application of paraloid B72 (thinned with toluene) at a rate of $3 \%, 5 \%$ and $7 \%$ respectively and application of silane based polymer (water repellent).

Table 2: Results of the tests performed on the stone.

\begin{tabular}{|l|c|c|c|c|c|}
\hline & $\begin{array}{c}\text { Com. Str. } \\
(\mathrm{Mpa})\end{array}$ & $\begin{array}{c}\text { Frost } \\
\text { Loss (\%) }\end{array}$ & $\begin{array}{c}\text { Abrasion } \\
(\%)\end{array}$ & $\begin{array}{c}\text { Specific } \\
\text { Weight } \\
(\text { ton/m }\end{array}$ & $\begin{array}{c}\text { Water. } \\
\text { Abs (\%) }\end{array}$ \\
\hline Original stone & 37.42 & 0.05 & 12.30 & 2.1 & 9.7 \\
\hline $\begin{array}{l}\text { Original stone on which chem. } \\
\text { mat. is applied }\end{array}$ & - & 0.02 & 3.0 & 2.0 & 6.1 \\
\hline $\begin{array}{l}\text { Stone used in rest. project } \\
\text { (Diyarbakır Hani Quarry) }\end{array}$ & 100.1 & 0.02 & 4.95 & 2.6 & 1.1 \\
\hline
\end{tabular}

Data obtained through the research excavations made manually around the bridge with due diligence and façade cleaning works are deemed to be the most important sources for the restitution project. During restitution works, the book written by C. Çulpan and titled as "Turkish Stone Bridges", by G. Tunç under the title of "Our Stone Bridges" and by F. İlter titled as Anatolian Turkish Bridges until Ottoman Era" for references to be made to the researches in the field of Art History.

\subsection{Restoration project}

The restoration project produced for Malabadi Bridge was prepared in the manner to take into account the least intervention principle in order to prevent further 
deteriorations, augment its strength against natural conditions and time and protect the original form of the same.

Restoration project was produced in the manner to include the scraping of the cement base plaster on the surfaces of the bridge repaired in 1954 through 1985 several times through mechanical methods diligently, interventions to the deteriorations observed on the unplastered stones in the main vault at the springer level and execution of the stone completion works in accordance with the conservation report, replacement of the liquefied or deficient materials with new materials, completion of deficient archivolts and parapet stones in accordance with the original form of the bridge.

\section{Restoration works}

After approval of the Restoration Projects by the Regional Conservation Board for Cultural Assets in Diyarbakır on July 17, 2012, necessary safety measures were taken and restoration works were commenced in accordance with the work schedule. In this context, the conservation works executed on the bridge are to be described under the following topics: 1) Cleaning, 2) Gap Filling, 3) Plastic Repair, 4) Adhesion and 5) Surface Protection.

\subsection{Cleaning}

\subsubsection{Cleaning of cement base plasters}

Prior to plaster scraping works, sectional cleaning works were executed through mechanical methods at the locations previously determined and approved by the Conservation Board in Diyarbakır with the letter of approval dated April 20, 2011 in order to understand whether or not the application is to be damage to the original pattern of the stone behind the plaster.

In this context, after setting up the scaffolding, the cement based plasters at 3 to $12 \mathrm{~m}$ thickness applied on the surfaces of the bridge during late period repairs were removed through mechanical methods with due diligence. After completion of the plaster scraping works, the residues of cement on the exposed surfaces of the stone were removed through mechanical method while the joint channels opened during late period repairs on the surfaces of the stone were left as they were.

In addition, the stones deficient on the bridge were completed with lime stones supplied from Hani Quarry in the District of Diyarbakır for which the tests were performed within the scope of the technical research studies as the compressive strength of such stones is high and the abrasion rate of the same is low (Table 2).

\subsubsection{Cleaning of the fauna based deteriorations within main arch intrados}

In order to complete the conservation process for the arch intrados, a steel platform supported by the rocks on which the main arch with $40.86 \mathrm{~m}$ span is settled was first established. The bird nests within the arches were washed away, the surfaces with blackened dirt layer were cleaned with the help of soft plastic brushes in dry 
form, and brushed with plastic brushed subsequent to application of pressurized water to remove the dirt and dust.

\subsubsection{Cleaning the limestone tablets}

After cleaning the soil and cement residues on the limestone tablets of the bridge through mechanical methods, the blackened dirt crusts caused by the harmful gases in the atmosphere were removed from the surfaces by way of pulps engrained in the ammonium bicarbonate (Table 1; Procedure 1). Thereafter, the surfaces were cleaned through water and brushes.

\subsubsection{Cleaning the lichens and biocide application}

The lichens on the archivolt, flood splitter cones and parapet caps of the bridge brushed by way of soft plastic brushes in dry and wet form and washed through low pressurized water while the lichen preventer (biocide) was sprayed on the surfaces through injectors.

\subsection{Gap filling}

\subsubsection{Conservation of the cracks}

After completion of the cleaning works, the cracks on surfaces of the stones within intrados were filled with grout specifically prepared for such cracks and proposed in the contents of the conservation report through spatula (Table 1; Procedure 2),while the surface was smoothened through a damp sponge after compaction with brush.

\subsubsection{Microinjection application}

For the wider and deeper cracks on the surfaces of the stones, such cracks were first covered with plasticine and grout injected into the same with the help of an injector (Table 1; Procedure 3) and after waiting one full day, the plasticine on the wall was removed and the deficient stone surfaces were completed with the grout used in the repair of the cracks (Table 1; Procedure 2).

\subsection{Plastic repairs}

\subsubsection{Conservation of the statue}

The cement residues on the statue to the upstream of the bridge were removed through mechanical methods using small hand tools while the deficient sections were filled with imitation grout (Table 1; Procedure 5). After compaction of the fake grout filled on the cracks at an appropriate level through a fine spatula, with the use of a brush, their surfaces were burnished with a damp sponge.

\subsection{Adhesion}

\subsubsection{Stone complementation with reinforcement}

Detached or segregated large stone masses were fully removed in the first instance and the soil behind such stone masses was cleared together with the bird craps while the detached mass was fixed on the primal stone. After settling the stone, two each holes were opened on the surface of the stone at a depth of $30-40 \mathrm{~cm}$ 
with the help of a non-percussion drill while the stone was removed and cleaned with a brush. Plasticine was employed on the outer sections of the holes thus opened and epoxy glue was applied to fill the interior sections of the holes. Stainless steel reinforcement was gently settled on the holes filled with epoxy grout and 1 day time was awaited for it to dry. Thereafter, epoxy grout was injected into the holes on the cracks and the aesthetic joints were formed through imitation grout. (Table 1; Procedure 6).

\subsubsection{Stone complementation without reinforcement}

The detached or segregated minor stone pieces were fully removed while the soil and residual substances behind such stones were brushed while the detached mass was fixed on the primal stone. The adhesive material with epoxy was filled in the manner not to effuse the material (Table 1; Procedure 7) thereafter the epoxy was left to dry for 1 full day and aesthetic joint was formed through the grout injection specifically prepared for cracks.

\subsection{Surface protection}

\subsubsection{Surface protection plasters}

The surface protection plasters prepared for the surfaces of the stones the abrasion capacity of which is relatively high in order not to give way to any re-occurrence and problematic case due to rain, moisture, heat and frost were brushed on the surfaces of the stones and repeated three times. (Table 1; Procedure 8).

\subsubsection{Conservation of the relief of the sun}

To the downstream of the bridge, the cement base plasters on the relief of the sun on the flood splitter cone were cleaned through mechanical methods by using small hand tools while acrylic emulsion was applied on the capillary cracks with the help of the injectors and sponges. (Table 1; Procedure 4), followed by the application of surface protection plaster through brushes (Table 1; Procedure 8).

\section{Conclusion}

The bridges the major function of which is to provide accession should first be stabilized in order to allow safe passageway. The restoration works to be carried out on the arch stone bridges which are proven to be durable against the factors such as earthquakes, dams, variable water flows and heavy traffic over the centuries should comply with the original construction techniques, protection of the material wise properties and the "least intervention" principle.

Considering that the scientific and technical data of all kind which may provide assistance in the repair and conservation of the historic bridges which are of great importance in view of technology history and cultural history should be made available and the experiences attained should be shared, this paper aims to provide contribution for the restoration works which should be executed with the involvement of various disciplines and different professionals. 


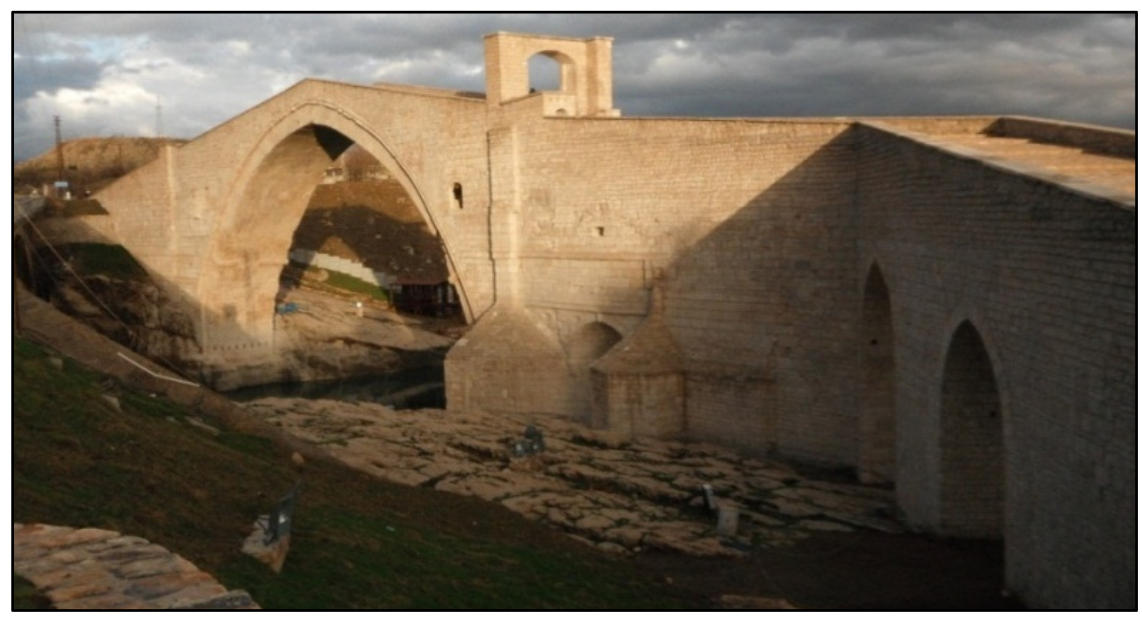

Figure 8: Historical Malabadi Bridge after restoration.

\section{Acknowledgements}

KGM has provided supervision and consultancy services for the Restoration Project prepared by the Employer, namely Zülfikar Halifeoğlu.

Analysis of the Original Stone: The tests are performed at the laboratories of Istanbul University, Faculty of Letters, Division of Movable Cultural Assets and Conservation, Department of General Conservation and Repairs/Istanbul and Laboratories of General Directorate of Highways (KGM), Department of Research and Development, Ankara which are the members of (Turkish Accreditation Agency, European Accreditation Union, International Laboratory Accreditation Union) with TS-EN-ISO 9000/9001 certification. New stone tests: are executed at KGM Laboratories Department of Research and Development, Ankara. Standard for Stone Tests: TS 699.

Conservation Report is issued by the laboratories of Istanbul University, Faculty of Letters, Division of Movable Cultural Assets and Conservation, Department of General Conservation and Repairs, Istanbul.

KGM has provided supervision and consultancy services for the bridge the restoration works of which were executed by the Contractor company namely Zülfikar Halifeoğlu.

Translation by H. İlhan Korkmaz.

\section{References}

[1] Çulpan C., Turkish Masonry Bridges, Publications of Turkish Historical Society, Ankara, Turkey, 1975.

[2] İlter, F., Anatolian-Turkish Bridges until Ottoman Era, KGM Publications, Ankara, Turkey, 1978. 
[3] Ortayl1, İ., Turkish Organizations and History of Management, Cedit Publications, Ankara, Turkey, 2007.

[4] KGM, Inventory of the Division of Historical Bridges, KGM Archives, Ankara, Turkey, 2014.

[5] KGM Map 2015.

[6] Google Earth 2015, https://earth.google.com/.

[7] KGM, Restoration Project and Technical Report for the Historical Malabadi Bridge, Technical Report Not Yet Published, KGM Archives, Archive Ankara, Registration No: B.09/I.21/N.01/RUP-2009.

[8] Doğan, A., Sert, H., Earthquakes and Arched Stone Bridges the Strength of which is Proven Through Long Lasting History, Seismic Protection of Cultural Heritage, WCCE-ECCE-IMO 2nd Joint Conference, Antalya, Turkey; pp. 397-417, 2011.

[9] Doğan A., Sert, H., Yılmaz, S., Partal, E.M., Demirci, H., Avşin, A., Nas, M., Turan, G.S., Determination of the Original Construction Systems of the Historical Bridges and Technical Researches for Material Analysis and Results, 6th Architectural Materials Congress (November 7-9, 2012) Book of Papers, TMMOB Chamber of Architects İstanbul Büyükkent Branch Office, İstanbul, Turkey; pp. 121-137, 2012.

[10] Doğan, A., Sert, H., Yilmaz, S., et al., Determination of the Original Construction Systems of the Historical Bridges and Technical Researches for Material Analysis and Results, Journal of Materials in Architecture, Architecture and Construction Materials, Year: 8, Issue: 24, TMMOB Chamber of Architects, Istanbul, Turkey; pp. 39-47, 2013.

[11] Ener, E., Sert, H., ACE 2010-See-168, Technical Researches for the Restoration of The Stone Bridges and the Assessment of the Outcomes, 9th Int. Congress on Advances in Civil Engineering, Book of Papers (September 27-30, 2010), KTÜ, Trabzon, Turkey; pp. 1-9, 2010.

[12] Sert, H. et al., Specifications, Legislation, Inventory, Projects and Maintenance - Repair of Historical Bridges, KGM Publication No: 268, KGM Printing House, Ankara, Turkey, 2009.

[13] Sert, H., Y1lmaz, S. vd., Restoration - Conservation Works Carried Out At Historical Malabadi Bridge, 9th International Symposium on the Conservation of Monuments in the Mediterranean Basin, Improvements in Conservation and Rehabilitation - Integrated Methodologies, Ankara, Turkey, 3-5 June 2014.

[14] Sert, H., Y1lmaz, S. vd., Restoration Works of Masonry Arch Bridges In Anatolia And Balkans, İstanbul Bridge Conf. 2014 (iBridge 2014), İstanbul, Turkey, 11-13 August 2014. 